\title{
Papers
}

\section{Does the cannabinoid dronabinol reduce central pain in multiple sclerosis? Randomised double blind placebo controlled crossover trial}

\author{
Kristina B Svendsen, Troels S Jensen, Flemming W Bach
}

\begin{abstract}
Objective To evaluate the effect of the oral synthetic $\delta$-9-tetrahydrocannabinol dronabinol on central neuropathic pain in patients with multiple sclerosis.

Design Randomised double blind placebo controlled crossover trial.

Setting Outpatient clinic, University Hospital of Aarhus, Denmark.

Participants 24 patients aged between 23 and 55 years with multiple sclerosis and central pain.

Intervention Orally administered dronabinol at a maximum dose of $10 \mathrm{mg}$ daily or corresponding placebo for three weeks (15-21 days), separated by a three week washout period.

Main outcome measure Median spontaneous pain intensity (numerical rating scale) in the last week of treatment.

Results Median spontaneous pain intensity was significantly lower during dronabinol treatment than during placebo treatment (4.0 (25th to 75 th centiles 2.3 to 6.0$)$ v 5.0 (4.0 to 6.4), $\mathrm{P}=0.02$ ), and median pain relief score (numerical rating scale) was higher (3.0 ( 0 to 6.7$)$ v 0 ( 0 to 2.3$), \mathrm{P}=0.035)$. The number needed to treat for $50 \%$ pain relief was $3.5(95 \%$ confidence interval 1.9 to 24.8 ). On the SF-36 quality of life scale, the two items bodily pain and mental health indicated benefits from active treatment compared with placebo. The number of patients with adverse events was higher during active treatment, especially in the first week of treatment. The functional ability of the multiple sclerosis patients did not change.

Conclusions Dronabinol has a modest but clinically relevant analgesic effect on central pain in patients with multiple sclerosis. Adverse events, including dizziness, were more frequent with dronabinol than with placebo during the first week of treatment.
\end{abstract}

\section{Introduction}

Pain is an important symptom accompanying multiple sclerosis; acute or chronic pain syndromes occur in $30-80 \%$ of patients. ${ }^{1-6}$ The many different types of pain seen in multiple sclerosis include musculoskeletal pain, pain associated with spasms, and central pain from sclerotic plaque lesions affecting pain pathways in the central nervous system. The reported prevalence of central pain in multiple sclerosis patients is around 33\%. ${ }^{7}$

In recent years the efficacy of cannabinoids in the treatment of multiple sclerosis symptoms, including pain and spasticity, has been discussed. Cannabinoids have been shown to decrease allodynia or hyperalgesia in various animal pain models, including inflammatory pain, ${ }^{89}$ neuropathic pain, ${ }^{10}{ }^{11}$ capsaicin-induced pain, ${ }^{12-14}$ and cancer pain. ${ }^{15}$

The analgesic effects may be produced by both central and peripheral mechanisms. ${ }^{80-14} 16-18$ One theory is that cannabinoids inhibit release of transmitter from primary afferents ${ }^{19}$; another is that they activate descending modulatory pathways. ${ }^{20}$

Clinical studies evaluating the analgesic action of cannabinoids in humans are sparse. Clinical reports indicate that cannabinoids may alleviate pain in different pain conditions, including multiple sclerosis related pain. ${ }^{21-23}$ Only a few randomised clinical trials are available. ${ }^{24-27}$ Three randomised studies that evaluated the efficacy of cannabinoids on different neurogenic symptoms, including pain, have recently been published. ${ }^{27-29}$ Two of these studies included patients with multiple sclerosis. $^{28}{ }^{29}$ A large multicentre randomised placebo controlled study including 630 multiple sclerosis patients found an improvement in pain after 15 weeks of treatment with cannabinoids (oral $\delta$-9-tetrahydrocannabinol or cannabis extract). ${ }^{29}$ The primary outcome measure of this study, however, was spasticity, and no information was given about subtypes of pain. Another randomised placebo controlled single patient crossover study including 24 patients with neurogenic symptoms (18 multiple sclerosis patients) found that extract of whole plant cannabis ( $\delta$-9-tetrahydrocannabinol and cannabidiol) administered by sublingual spray improved pain. ${ }^{28}$ Twelve of the 20 patients completing the study had neuropathic pain. The third study included a group of patients $(n=21)$ with many different neuropathic pain conditions (mainly peripheral neuropathic pain). ${ }^{27}$ In this randomised placebo controlled crossover study, one week of treatment with the synthetic cannabinoid CT-3 reduced neuropathic pain.

None of the previous studies has specifically explored the effect of cannabinoids on pain caused by central lesions in multiple sclerosis. We aimed to evaluate the efficacy of the synthetic $\delta$-9-tetrahydrocannabinol dronabinol on central pain in multiple sclerosis patients in a randomised placebo controlled study. The objective was to provide better treatment options for central pain in multiple sclerosis, and we hypothesised that dronabinol would reduce central pain in multiple sclerosis.

\section{Methods}

\section{Protocol}

We recruited participants from the population of patients with definite multiple sclerosis in Aarhus County, Denmark. ${ }^{30}$ We recruited patients partly from the outpatient multiple sclerosis clinic at the University of Aarhus and partly from responders 
$(n=627)$ to a postal survey undertaken among all patients with multiple sclerosis in Aarhus County in $2001 .^{6}$ In the multiple sclerosis clinic two chief consultants informed eligible patients about the study. One of the investigators (KBS) interviewed by telephone the patients with pain identified through the postal survey. Patients with suspected central pain had a clinical examination in the pain clinic.

Inclusion criteria were a diagnosis of multiple sclerosis (clinical definite multiple sclerosis and laboratory supported definite multiple sclerosis ${ }^{30}$ ), age between 18 and 55 years, and central pain at the maximal pain site with a pain intensity score $\geq 3$ on a 0-10 numerical rating scale. A doctor (KBS) assessed central pain after a clinical examination. The criterion for central pain was pain in a body territory with abnormal sensation to pinprick, touch, warmth, or cold, evaluated by the bedside, or quantitative sensory testing corresponding to at least one lesion in the central nervous system. ${ }^{71}$ We did not include patients with musculoskeletal disorders, peripheral neuropathic pain (caused by a lesion in nerve root, plexus, or peripheral nerve), or visceral pain at the maximal pain site. We allowed concurrent spasm related pain if the patient was able to distinguish spasm related pain and central pain. We allowed additional pain outside the maximal pain site if pain intensity was low and distinguishable from the central pain. Exclusion criteria were hypersensitivity to cannabinoids or sesame oil; heart disease; mania, depression, or schizophrenia; previous or present alcohol or drug misuse; treatment with tricylic antidepressants, anticholinergic agents, antihistamine, or central nervous system depressant drugs (with the exception of spasmolytic drugs); use of analgesic drugs except paracetamol; pregnancy or lactation; sexually active women without reliable contraception; patients unable to cooperate or complete the study; participation in other clinical trials within the previous month; use of marihuana within the three months before the study; and unwillingness to abstain from the use of marihuana during the entire period. The patients consented to participate on the basis of verbal and written information.

We designed the study as a randomised double blind placebo controlled crossover trial. At study entry we obtained a medical history and did a full neurological and physical examination, including electrocardiography. We allocated patients to treatment after a one week baseline period. We planned for the patients to receive three weeks' (18-21 days') treatment with dronabinol and three weeks' (18-21 days') treatment with placebo, with a washout period of at least 21 days between the treatment periods. Any analgesic drug (except paracetamol) was discontinued at least one week before the first visit.

During the baseline period and the two treatment periods the patients recorded pain intensity, use of escape medication, and adverse events in a diary. They recorded assessment of pain relief at the end of each treatment period. At the end of the baseline period and at the end of each treatment period we administered quantitative sensory tests, a health related quality of life questionnaire (SF-36), and the expanded disability status scale. ${ }^{32}$ At the end of the study we asked the patients to identify the treatment period in which they received the active medication and which of the two treatments they preferred. We did a safety telephone follow up three to seven days after the last visit.

We administered dronabinol as $2.5 \mathrm{mg}$ capsules and used dosage escalation. The initial dose was $2.5 \mathrm{mg}$ daily, and the dose was increased by $2.5 \mathrm{mg}$ every other day to a maximum dose of $5 \mathrm{mg}$ (two capsules) twice daily. Placebo capsules were administered as identical looking capsules. The active capsules contained dronabinol solution in sesame oil, and the placebo capsules contained pure sesame oil. After 18-21 days of treatment we discontinued treatment without tapering. If adverse events occurred we reduced the dose to a minimum of $2.5 \mathrm{mg}$ daily. The investigational drug (Marinol; dronabinol tetrahydrocannabinol) and placebo were manufactured for Solvay by Banner Pharmacaps, USA, and packaged and labelled by IPC-Nordic, Denmark.

\section{Assignment and masking}

We assigned patients to treatment sequence by using a computer generated randomisation code with a block size of six prepared by IPC-Nordic. Investigators allocated patients consecutively by time of inclusion at the study site. Both investigators and patients were blinded. One investigator (KBS) enrolled all participants and allocated them to treatment.

We administered both active treatment and placebo as white capsules (soft gelatin capsules) in identical containers. The taste and smell of the capsules did not differ. Sealed, completely opaque code envelopes containing information about treatment sequence for each patient were present at the study site. The code envelopes were returned unopened to the monitor after termination of the study. We maintained blinding until the data analysis was completed.

\section{Assessments}

The predefined primary outcome measure was median spontaneous pain intensity in the last week of treatment. Secondary outcome measures were median radiating pain intensity in the last week of treatment, pain relief, use of escape medication, patient preference, health related quality of life (SF-36), expanded disability status scale score, and quantitative sensory testing.

We asked the patients to assess pain intensity and pain relief at the maximal pain site throughout the study. They assessed pain intensity by using a numerical rating scale from 0 to 10 $(0=$ no pain, $10=$ worst imaginable pain $)$. They made the assessment twice daily in the diary during the baseline period and throughout each treatment period. They recorded pain relief on a numerical scale from 0 to $10(0=$ no pain relief, $10=$ best pain relief) at the end of each treatment period. The patients also recorded the number of paracetamol taken daily. We assessed health related quality of life by using the standard version of the SF-36 health survey. We administered the survey as an interview to all patients to avoid problems due to visual handicap. The same investigator (KBS) did all the interviews.

We did quantitative sensory testing at baseline and at the end of each treatment period. We did the tests at the maximal pain site and at the same site at all three visits. We assessed tactile sensitivity to single stimuli by using Von Frey hair (Semmes Weinstein Monofilaments, Stoelting Co, IL, USA). We defined the tactile detection threshold as the smallest force needed to bend a Von Frey hair that was just perceived and the tactile pain threshold as the least force needed to bend a Von Frey hair that was just felt as painful. We used at least three changes of direction (ascending and descending forces) to define the tactile detection threshold and two crossings to define the tactile pain threshold. We measured sensation of vibration over a bony part by using an electronic vibrameter (Somedic Sales AB, Sweden). We took the average of the vibration perception threshold and the vibration disappearance threshold as the vibration threshold. ${ }^{33}$ We used the average of three vibration thresholds in the analysis. We determined the cold detection threshold, heat detection threshold, cold pain threshold, and heat pain threshold with the Medoc Thermotest (TSA 2001, Israel) by using the method of limits. From a baseline temperature of $30^{\circ} \mathrm{C}$, temperatures changed at a rate of $1{ }^{\circ} \mathrm{C} / \mathrm{s}$ (cut-off limits at $50.5^{\circ} \mathrm{C}$ and $0{ }^{\circ} \mathrm{C}$ ). The patient 
pressed a button when he or she just felt cold, warmth, painful cold, and painful warmth (average of five measurements used in analysis).

To determine the pain-free sensitivity range in which cold and warm were perceived, we calculated the warm sensibility index and the cold sensibility index. ${ }^{34}$ We defined the cold sensibility index as "cold pain detection threshold-cold threshold/ cold pain detection threshold - reference temperature" and the warm sensibility index as "heat pain detection threshold-warm threshold/heat pain detection threshold-reference temperature."

We assessed the pressure pain threshold by using a handheld electronic pressure algometer (Somedic AB, Sweden) as described previously, ${ }^{35}$ with a circular probe of $1 \mathrm{~cm}^{2}$ and a pressure rate of $30 \mathrm{kPa} / \mathrm{s}$. The patient pressed a button when the pressure was just felt as painful. We used the average of three measurements in analysis. We evoked temporal summation to pinprick stimuli by repetitively tapping the skin with a stiff nylon filament driven by a computer controlled solenoid (Laboratory for Experimental Pain Research, Aalborg University, Denmark) at a rate of $2 \mathrm{~Hz}$ for 1 minute. ${ }^{36}$ We assessed pain intensity before and after stimulation. We considered temporal summation to be present when pain intensity increased during the stimulation. We assessed dynamic touch evoked pain by stroking the painful skin area twice with a pellet of cotton wool $(1-2 \mathrm{~cm} / \mathrm{s})$. We assessed cold evoked pain by applying an acetone drop on the skin; patients assessed the pain on a 0-10 numerical scale before and after the stimulus. We considered allodynia (to dynamic touch or cold) to be present if pain was provoked or worsened by the stimulus and pain intensity after stimulation was $\geq 3$.

Patients used their own words to record adverse events in their dairies during each treatment period. If a patient reported the same adverse events more than once and the events were separated by time, we considered each episode as one event.

\section{Data analyses and statistics}

For the daily pain scale ratings we determined a median value for the third week of treatment. If a patient stopped the treatment prematurely we used the last week of treatment in the analysis according to the principle of intention to treat.

We coded and summed the item scores in SF-36 and transformed them to a scale of 0 (poor health) to 100 (optimal health). We handled missing data in the SF-36 according to the manual. ${ }^{37}$

We calculated the number needed to treat as the reciprocal of the difference between the proportions with a pain relief score (numerical rating scale) $\geq 5$ in the two groups. We obtained the $95 \%$ confidence interval as the reciprocal of the confidence interval of the absolute risk reduction. ${ }^{38}$

We compared treatment effects (pain intensity, pain relief, escape medication, SF-36, expanded disability status scale, and quantitative sensory testing) by using Koch's adaptation of the Wilcoxon-Mann-Whitney rank sum test allowing for a possible period effect. ${ }^{39}$ We used the Hodges-Lehmann estimator (a nonparametric method linked to the Wilcoxon test ${ }^{39}$ ) to provide a point estimate and $95 \%$ confidence intervals for treatment effect. We used the Mainland-Gart test to analyse binary data (temporal summation, allodynia, treatment preference, adverse events). We used the Mann-Whitney test to test for a possible carryover effect. We used Fisher's exact test to compare the patients' guesses of active treatment arm. We considered $\mathrm{P}<0.05$ to be significant for the primary outcome measure.

We considered a $25-30 \%$ pain reduction from baseline to be clinically relevant in this study. ${ }^{40}$ Expecting an average pain intensity at baseline between 5 and 6 on the 0 - 10 numerical rating scale, $\mathrm{a} \geq 1.5$ point difference between treatments would correspond to a $25-30 \%$ reduction from baseline. Considering a difference in spontaneous pain intensity of at least 1.5 points on the $0-10$ numerical rating scale between dronabinol and placebo treatments, we expected 23 patients to be sufficient to obtain a statistical power greater than $90 \%(\alpha=0.05)$ (SD 2.5 was obtained from unpublished data from other patients with central pain). ${ }^{41}$

\section{Results}

\section{Participants}

Patients were recruited to the study in the period 27 February to 21 May 2002. The last telephone follow up took place on 26 July 2002. We screened 25 patients for the study (fig 1). One patient had an abnormal electrocardiogram and was not included. All enrolled participants $(n=24)$ completed the study protocol. Table 1 gives the characteristics of the participants.

One participant claimed that the container of study medication was empty after 15 days of treatment in both periods. We did not include the results of the SF-36 and quantitative sensory testing from this patient in analysis, because the patient ran out of treatment a week before the measurements were made.

One patient had a muscle sprain (provoked by a sudden movement) on day 14 in the second treatment period (active medication). The pain due to the sprain was different from the patient's normal pain, but she assessed the intensity of this new pain in the diary. On visit 4 (on day 18) the patient was asked to assess retrospectively the intensity of her normal pain from day 14 to day 18. We used the patient's retrospective assessment of spontaneous pain in the calculation of the median pain intensity of the last week of the second treatment period.

\section{Primary outcome measure}

We observed no significant carryover effect for the primary outcome measure $(\mathrm{P}=0.24)$. The median spontaneous pain intensity during the last week of treatment was significantly lower during dronabinol treatment than during placebo treatment $(4.0$ (25th to 75 th centiles 2.3 to 6.0 ) $v 5.0$ (4.0 to 6.4), $\mathrm{P}=0.02$ ) (fig 2). The estimated difference in pain scores between dronabinol and placebo treatments was $-0.6(95 \%$ confidence interval -1.8 to 0) (Hodges-Lehmann estimator).

In the group of patients randomised to active medication in the first period the change in spontaneous pain intensity from baseline was -1.0 (25th to 75 th centiles -1.9 to -0.1 ) during dronabinol treatment and $0(-2.0$ to 0$)$ during placebo treatment. In the group of patients randomised to placebo in first period the change in pain from baseline was $-1.5(-2.8$ to $-0.3)$ during dronabinol treatment and 0 (0 to 0.9$)$ during placebo treatment. The estimated relative difference in pain reduction from baseline between dronabinol and placebo treatments was $-20.5 \% \quad(95 \%$ confidence interval -37.5 to -4.5$)$ (Hodges-Lehmann estimator).

\section{Secondary outcome measures}

Table 2 shows the secondary outcome measures. Median radiating pain intensity during the last week of treatment was lower during dronabinol treatment than during placebo treatment, and a higher pain relief score was obtained during dronabinol treatment than during placebo treatment. On the basis of pain relief scores, the number of patients that needed to be treated for one additional case of 50\% pain relief was 3.45 (95\% confidence interval 1.9 to 24.8). No differences between treatments occurred 


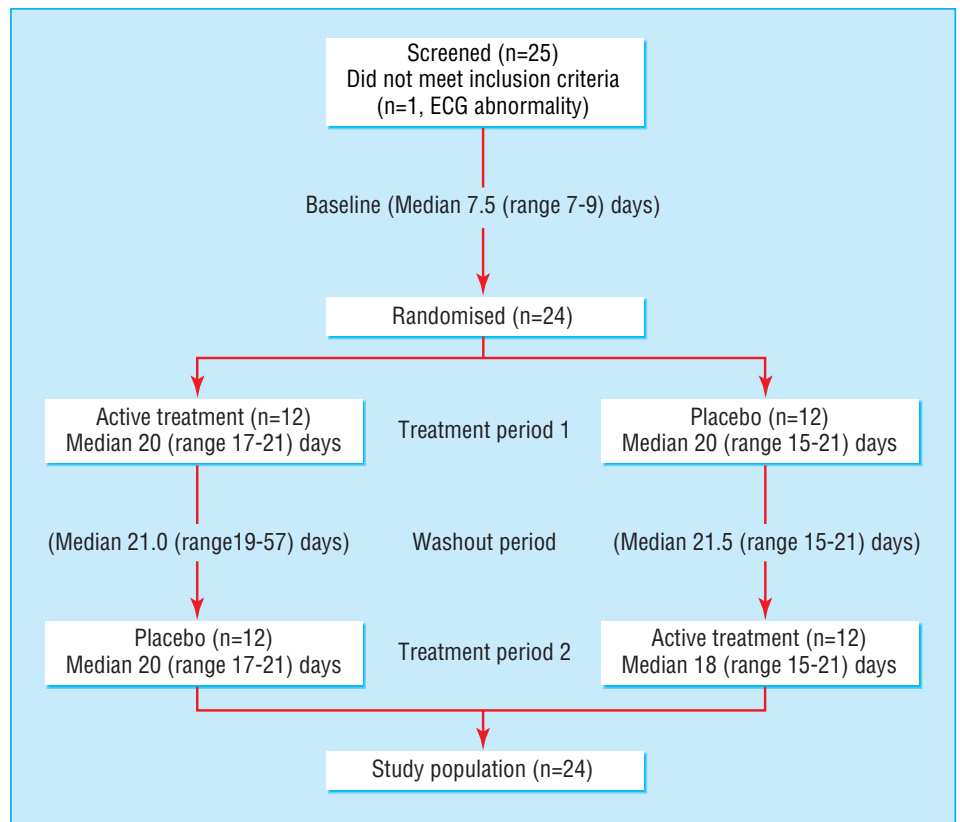

Fig 1 Flow diagram of patients enrolled in study. ECG=electrocardiogram

in period preference, escape medication, or expanded disability status scale score.

The pressure pain threshold was higher after dronabinol treatment than after placebo treatment. No differences between treatments occurred in cold sensibility, warm sensibility, tactile detection, tactile pain detection, vibration sense, temporal summation, or mechanical and cold allodynia. On the SF-36, the patients scored slightly higher (better) in the bodily pain and mental health domains during dronabinol treatment than during placebo treatment.

\section{Adverse events}

Adverse events were more common during dronabinol treatment than during placebo treatment. During dronabinol

\section{Table 1 Characteristics of participants}

\begin{tabular}{lc} 
Characteristic & No or median (range) (n=24) \\
\hline Age (years) & $50(23-55)$ \\
\hline Sex (male/female) & $10 / 14$ \\
\hline Duration of disease (years since diagnosis) & $(0.3-25.0)$ \\
\hline Disease course: & 9 \\
\hline Relapsing-remitting & 9 \\
\hline Secondary progressive & 6 \\
\hline Primary progressive & $6.0(2.5-6.5)$ \\
\hline Expanded disability status scale score at inclusion & 4.5 \\
\hline Duration of pain (years) & $5.3-12.0)$ \\
\hline Intensity of pain at inclusion (numerical rating & $(3.0-8.0)$ \\
scale) & \\
\hline Site of pain: & 16 \\
\hline Lower extremities & 4 \\
\hline Upper extremities & 2 \\
\hline Back & 2 \\
\hline Chest & 17 \\
\hline Description of pain: & 13 \\
\hline Pricking & 3 \\
\hline Hot or burning & 3 \\
\hline Tingling & 3 \\
\hline Tight & 7 \\
\hline Dull & \\
\hline Other & \\
\hline & \\
\hline
\end{tabular}

treatment $23(96 \%)$ patients had adverse events compared with $11(46 \%)$ patients during placebo treatment $(\mathrm{P}=0.001$, Mainland-Gart test) (table 3). Eleven of the patients had adverse events in both treatment periods; none had adverse events during placebo treatment only. The number of patients with adverse events was higher during the first week of dronabinol treatment than during the last week of treatment.

During active treatment four $(17 \%)$ patients had their doses reduced (three patients to $7.5 \mathrm{mg}$ daily and one patient to $5 \mathrm{mg}$ daily) because of intolerable adverse events. The reduction of dose decreased the side effects for all four patients. The rest of
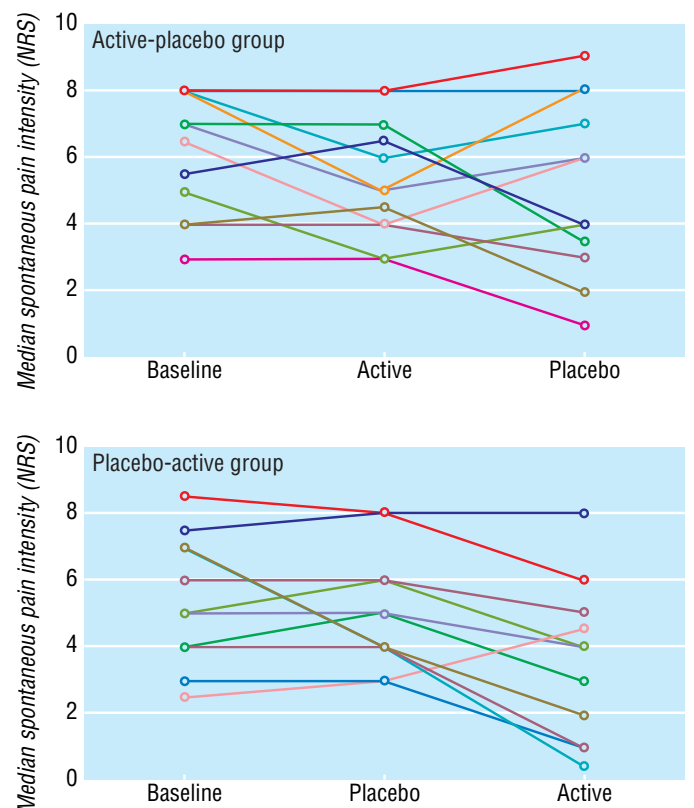

Fig 2 Spontaneous pain intensity during one week baseline, last week of active treatment, and last week of placebo treatment. Each line represents one patient. Active-placebo group=patients randomised to active medication in first treatment period $(n=12)$; placebo-active group=patients randomised to placebo in first treatment period $(n=12)$; NRS=numerical rating scale 
Table 2 Primary and secondary outcome measures. Values are medians (25th to 75th centiles) unless stated otherwise

\begin{tabular}{|c|c|c|c|c|c|c|}
\hline \multirow[b]{2}{*}{ Measure } & \multicolumn{2}{|c|}{ Active-placebo group } & \multicolumn{2}{|c|}{ Placebo-active group } & \multirow[b]{2}{*}{ Difference $(95 \% \mathrm{CI})^{*}$} & \multirow{2}{*}{$\begin{array}{c}P \text { value (active } \\
v \text { placebo) } \dagger\end{array}$} \\
\hline & Period 1(A) & Period 2(P) & Period 1(P) & Period 2(A) & & \\
\hline $\begin{array}{l}\text { Reduction in median } \\
\text { spontaneous pain from } \\
\text { baseline (numerical } \\
\text { rating scale) }\end{array}$ & $-1.0(-1.9$ to -0.1$)$ & $0(-2.0$ to 0$)$ & 0 (0 to 0.9$)$ & $-1.5(-2.8$ to -0.3$)$ & $-0.6(-1.8$ to 0$)$ & 0.02 \\
\hline $\begin{array}{l}\text { Pain relief (numerical rating } \\
\text { scale) }\end{array}$ & $3.0(0.0$ to 7.5$)$ & $0.5(0$ to 5.3$)$ & $0(0$ to 0$)$ & 4.0 (1.3 to 6.8$)$ & 2.5 (0.5 to 4.5$)$ & 0.035 \\
\hline $50 \%$ pain relief (No (\%)) & $5(42)$ & $3(25)$ & $1(8)$ & $6(50)$ & - & 0.08 \\
\hline $\begin{array}{l}\text { Radiating pain, diary } \\
\text { (numerical rating scale) }\end{array}$ & $1.8(0.0$ to 6.0$)$ & 4.8 (0.0 to 5.8$)$ & $1.5(0.0$ to 4.0$)$ & 0.8 (0.0 to 2.0$)$ & $-0.6(-1.3$ to 0$)$ & 0.039 \\
\hline $\begin{array}{l}\text { Treatment preference (№ } \\
(\%))\end{array}$ & $5(42)$ & $5(42)$ & $1(8)$ & $9(75)$ & - & 0.14 \\
\hline $\begin{array}{l}\text { Escape medication (daily No } \\
\text { of paracetamol) }\end{array}$ & 0 (0 to 3.5) & 0 (0 to 3.5) & $0(0$ to 0$)$ & $0(0$ to 0$)$ & 0 & 0.66 \\
\hline $\begin{array}{l}\text { Expanded disability status } \\
\text { scale }\end{array}$ & $6.0(4.5$ to 6.4$)$ & 6.0 (4.6 to 6.4$)$ & 5.8 (3.6 to 6.0$)$ & 5.5 (4.3 to 6.0$)$ & 0 & 1.00 \\
\hline \multicolumn{7}{|l|}{ Quantitative sensory testingf } \\
\hline Cold detection threshold & 23.7 (16.4 to 26.9) & 24.2 (20.8 to 26.1) & 24.3 (22.2 to 27.0$)$ & 26.5 (24.0 to 28.3) & $0.5(-0.6$ to 1.8$)$ & 0.44 \\
\hline Warm detection threshold & 41.5 (35.1 to 45.9 ) & 38.8 (34.6 to 44.2 ) & 40.1 (34.4 to 47.0 ) & 43.5 (33.5 to 46.4 ) & 0.1 ( -0.1 to 1.8$)$ & 0.83 \\
\hline Cold pain threshold & 9.6 (0.2 to 22.2$)$ & 12.8 (1.3 to 22.5$)$ & 12.9 (5.4 to 22.8 ) & 20.4 (0.0 to 23.2 ) & 0.0 (-1.1 to 2.1$)$ & 1.00 \\
\hline Heat pain threshold & 45.3 (42.6 to 46.5$)$ & 43.2 (40.7 to 47.9$)$ & 46.6 (43.3 to 48.5$)$ & 46.4 (43.1 to 49.4 ) & $0.3(-0.4$ to 1.3$)$ & 0.46 \\
\hline Cold sensibility index & 0.49 (0.36 to 0.61$)$ & $0.51(0.26$ to 0.70$)$ & 0.61 (0.04 to 0.76$)$ & 0.75 (0.14 to 0.80$)$ & $0.1(-0.0$ to 0.2$)$ & 0.34 \\
\hline Warm sensibility index & 0.22 (0.08 to 0.63$)$ & 0.20 (0.10 to 0.59$)$ & $0.31(0.07$ to 0.70$)$ & 0.29 (0.16 to 0.57$)$ & $0.0(-0.1$ to 0.1$)$ & 0.52 \\
\hline $\begin{array}{l}\text { Tactile detection threshold } \\
\text { (g) }\end{array}$ & 1.8 (0.6 to 3.6$)$ & 1.5 (0.6 to 3.6$)$ & $1.2(1.2$ to 8.5$)$ & $1.2(0.7$ to 3.6$)$ & $0.0(-1.1$ to 0.7$)$ & 0.95 \\
\hline $\begin{array}{l}\text { Tactile pain detection } \\
\text { threshold }(\mathrm{g})\end{array}$ & 13.4 (6.2 to 354.0$)$ & 42.2 (4.9 to 281.8) & 28.8 (11.7 to 75.9 ) & 75.9 (5.5 to 125.9) & 0.0 (-4.1 to 23.9$)$ & 0.90 \\
\hline $\begin{array}{l}\text { Pressure pain threshold } \\
(\mathrm{kPa})\end{array}$ & 304 (157 to 421) & 216 (170 to 437) & 263 (213 to 403) & 343 (245 to 462) & 42.8 (1.0 to 78.5$)$ & 0.036 \\
\hline $\begin{array}{l}\text { Vibration threshold }(\mu \mathrm{m}) \\
\end{array}$ & 2.4 (1.7 to 75.2$)$ & $3.2(1.2$ to 19.3$)$ & 2.5 (1.4 to 34.3$)$ & 1.8 (1.1 to 33.3$)$ & 0.0 (-0.6 to 2.2$)$ & 0.88 \\
\hline $\begin{array}{l}\text { Temporal summation (№ } \\
(\%) \text { ) }\end{array}$ & $5(42)$ & $7(58)$ & $5 / 11(46)$ & $4 / 11(36)$ & - & 0.43 \\
\hline $\begin{array}{l}\text { Mechanical allodynia (No } \\
(\%)) \S\end{array}$ & $2(17)$ & $1(8)$ & $0(0)$ & $0(0)$ & - & \\
\hline Cold allodynia (No (\%)) & $5(42)$ & $3(25)$ & $5 / 11(46)$ & $4 / 11(36)$ & - & 1.00 \\
\hline \multicolumn{7}{|l|}{ SF-36‡ } \\
\hline Physical functioning & 40.0 (20.0 to 58.9 ) & 35.0 (16.3 to 45.0$)$ & 30.0 (20.0 to 60.0$)$ & 40.0 (25.0 to 55.0$)$ & 5.0 (0 to 7.5$)$ & 0.06 \\
\hline Role physical & 25.0 (0 to 50.0$)$ & 25.0 (0 to 93.8$)$ & 25.0 (25.0 to 100) & 50.0 (25.0 to 100.0$)$ & $0(-25.0$ to 12.5$)$ & 0.73 \\
\hline Bodily pain & 41.0 (22.0 to 62.0$)$ & 26.5 (21.3 to 48.5$)$ & 42.0 (31.0 to 51.0$)$ & 61.0 (42.0 to 74.0$)$ & 9.8 (0 to 21.5) & 0.037 \\
\hline General health & 43.5 (35.0 to 73.3 ) & 46.0 (25.0 to 74.5$)$ & 35.0 (27.0 to 62.0$)$ & 32.0 (25.0 to 57.0$)$ & $0(-6.0$ to 5.0$)$ & 0.95 \\
\hline Vitality & 42.5 (18.8 to 57.5$)$ & 27.5 (16.3 to 58.8) & 40.0 (25.0 to 55.0$)$ & 35.0 (30.0 to 45.0) & $2.5(-5.0$ to 10.0$)$ & 0.52 \\
\hline Social functioning & 100.0 (62.5 to 100.0) & 100.0 (53.1 to 100.0) & 75.0 (50.0 to 87.5$)$ & 87.5 (75.0 to 100.0$)$ & 6.3 (0 to 12.5) & 0.17 \\
\hline Mental health & 86.0 (72.0 to 95.0) & 84.0 (60.0 to 100.0$)$ & 72.0 (52.0 to 84.0) & 84.0 (68.0 to 88.0) & 8.0 (0 to 12.0$)$ & 0.023 \\
\hline Role emotional & 100.0 (75.0 to 100.0) & 100.0 (75.0 to 100.0) & 100.0 (66.7 to 100.0) & 100.0 (66.7 to 100.0) & $0(-33.0$ to 0$)$ & 0.46 \\
\hline
\end{tabular}

the patients had no need for dose reduction during active treatment and were all treated with $10 \mathrm{mg}$ daily. No patients had their dose reduced during placebo treatment.

The most common adverse events during dronabinol treatment were related to the central nervous system (dizziness, headache, tiredness) and the muskuloskeletal system (myalgia, muscle weakness) (table 3). Four patients had an aggravation of multiple sclerosis during the trial-one during dronabinol treatment, two during placebo treatment, and one during the washout period. The last patient was admitted to the hospital. The washout period of this patient was extended (57 days) because of the adverse event. The head of the multiple sclerosis clinic confirmed that the patient's neurological condition was stable before the second treatment period (placebo) was started.

\section{Assessment of blinding}

Sixteen $(67 \%)$ of the patients correctly identified the period in which they received active medication. Six $(25 \%)$ patients identi- fied the wrong period, and two (8\%) patients were unable to choose one of the treatments $(\mathrm{P}=0.19$, Fisher's exact test $)$.

Length of treatment periods and number of capsules taken The median treatment period was 20 (range 15-21) days for both active treatment and placebo. The median washout period was 21 (19-57) days. The average number of capsules taken was 62 (54-72) during active treatment and 66 (56-72) during placebo treatment.

\section{Discussion}

\section{Outcome}

Oral dronabinol, at a maximum dose of $10 \mathrm{mg}$ daily, reduced central pain in patients with multiple sclerosis. The primary outcome measure-median spontaneous pain intensity during the last week of treatment-was significantly reduced during dronabinol treatment compared with placebo. The difference 
Table 3 Adverse events during treatment with dronabinol and placebo. Values are numbers (percentages) of patients with adverse event, number of adverse events

\begin{tabular}{|c|c|c|}
\hline Adverse events & Dronabinol $(\mathrm{n}=24)$ & Placebo $(n=24)$ \\
\hline Central nervous system & 19 (79), 61 & 8 (33), 20 \\
\hline Dizziness or lightheadedness & $14(58)^{\star}, 26$ & 4 (17), 5 \\
\hline Tiredness or drowsiness & 10 (42), 12 & $6(25), 10$ \\
\hline Fatigue & $1(4), 2$ & $0(0), 0$ \\
\hline Balance difficulty & $2(8), 2$ & $0(0), 0$ \\
\hline Headache & 6 (25), 10 & $1(4), 1$ \\
\hline Migraine & $1(4), 1$ & $0(0), 0$ \\
\hline Speech disorders & $1(4), 1$ & $0(0), 0$ \\
\hline Feeling of drunkenness & $2(8), 5$ & $0(0), 0$ \\
\hline Sleep difficulty & $1(4), 1$ & $2(8), 2$ \\
\hline Multiple sclerosis aggravated & $1(4), 1$ & $2(8), 2$ \\
\hline Musculoskeletal system & $9(38), 13$ & $2(8), 2$ \\
\hline Myalgia & $6(25), 7$ & $1(4), 1$ \\
\hline Muscle weakness & $3(13), 3$ & $1(4), 1$ \\
\hline Limb heaviness & $1(4), 2$ & $0(0), 0$ \\
\hline Distortion of wrist & $1(4), 1$ & $0(0), 0$ \\
\hline Gastrointestinal disorders & 5 (21), 7 & 4 (17), 8 \\
\hline Mouth dryness & 3 (13), 3 & $0(0), 0$ \\
\hline Nausea & 3 (13), 4 & 4 (17), 5 \\
\hline Abdominal pain & 0 (0), 0 & $1(4), 3$ \\
\hline Cardiovascular disorders & 4 (17), 8 & $2(8), 4$ \\
\hline Palpitations & 4 (17), 8 & $2(8), 4$ \\
\hline Psychiatric disorders & $3(13), 4$ & $1(4), 1$ \\
\hline Euphoria & $3(13), 3$ & $0(0), 0$ \\
\hline Hyperactivity & $1(4), 1$ & $0(0), 0$ \\
\hline Nervousness & $0(0), 0$ & $1(4), 1$ \\
\hline Endocrine disorders & $1(4), 2$ & $0(0), 0$ \\
\hline Hot flushes & $1(4), 2$ & $0(0), 0$ \\
\hline Vision disorders & $0(0), 0$ & $1(4), 1$ \\
\hline Diplopia & $0(0), 0$ & $1(4), 1$ \\
\hline Whole body & 4 (17), 5 & $2(8), 2$ \\
\hline Anorexia & $1(4), 1$ & $0(0), 0$ \\
\hline Weight decrease & $1(4), 1$ & $0(0), 0$ \\
\hline Fever & $0(0), 0$ & $1(4), 1$ \\
\hline Chills & $1(4), 1$ & $0(0), 0$ \\
\hline Upper airway infection & $1(4), 1$ & $1(4), 1$ \\
\hline Tenderness in nose & $1(4), 1$ & $0(0), 0$ \\
\hline Total & $23(96)^{\star *}, 100$ & 11 (46), 38 \\
\hline $\begin{array}{l}\text { Adverse event in first } \\
\text { treatment week }\end{array}$ & $21(88)^{* \star} \dagger, 50$ & 8 (33), 23 \\
\hline $\begin{array}{l}\text { Adverse event in last treatment } \\
\text { week }\end{array}$ & 10 (42), 15 & $5(21), 7$ \\
\hline Severe adverse event & 3 (13), 3 & $1(4), 1$ \\
\hline
\end{tabular}

between treatments in pain reduction from baseline was around $21 \%$.

The intensity of radiating pain during the last week of treatment was also reduced, and the pain relief score was higher during dronabinol treatment than during placebo treatment. The number needed to treat for $50 \%$ pain relief was 3.5. The threshold for pain provoked by pressure was slightly higher with dronabinol treatment than with placebo. Two items of the SF-36, bodily pain and mental health, indicated benefits from active treatment compared with placebo. We made no statistical correction for multiple comparisons. However, the results of the secondary outcome measures supported the finding that dronabinol was superior to placebo in reducing pain.

\section{Study design}

The length of the treatment period may be debated. We chose three weeks as a compromise to ensure stability of the multiple sclerosis within the study period and to ensure that we were not looking at temporary effects. It could be argued that dronabinol ameliorated pain by an non-specific effect on bodily functions other than those directly linked to pain. However, dronabinol did not alter the functional multiple sclerosis disability score during the trial, and on the SF-36 general health profile the only improvements seen were in bodily pain and mental health. These observations suggest that dronabinol had a specific effect on pain.

The definition of central neuropathic pain is vague. ${ }^{31}$ We included only patients with sensory abnormalities at the maximal pain site, and we did not define spasm related pain as central pain as other authors have. ${ }^{7}$ We included patients with spasms only if they were able to distinguish spasm related pain and central pain. We instructed all patients throughout the study to assess pain only at the site that was most painful at study start and only that diagnosed as central pain. In this way we tried to ensure that only changes in central pain were assessed. However, we cannot exclude the possibility that some of the pain reduction was related to a decrease in spasm related pain. In addition, the higher mental health subscore on the SF-36 during dronabinol treatment may indicate that some of the benefit of dronabinol on pain may be due to a central effect.

\section{Clinical implications}

Whether the small reduction in pain intensity during dronabinol treatment seen in this study is clinically important can also be debated. However, the treatment of neuropathic pain conditions, and in particular those caused by central nervous system lesions, is difficult. ${ }^{40}$ Randomised trials evaluating oral treatment of central pain are limited. ${ }^{42}$ The pain reduction seen in this study is comparable to the effect of other drugs used in the treatment of neuropathic pain conditions. ${ }^{43}$

Even when a pain reduction on the numerical rating scale is small, the patient may find the reduction clinically important. Pain relief $\geq 33 \%$ was found to be a clinically important pain outcome measure in a study that included cancer patients. ${ }^{45}$ Defining a score of $\geq 3$ on the 0-10 numerical rating scale as $\geq 33 \%$ pain relief, $13(54 \%)$ patients in our study had $\geq 33 \%$ pain relief during dronabinol treatment compared with 5 (21\%) patients during placebo treatment.

\section{Adverse effects}

The number of patients with adverse events was higher during dronabinol treatment than during placebo treatment. However, no patients were withdrawn because of adverse events, and only four patients had their dose reduced during active treatment. The number of patients with adverse events decreased during active treatment, and in the last treatment week we found no significant difference in the number of patients with adverse events. This may be due to increasing tolerance to the drug over time. We obtained the adverse events from the patients' diaries, and this may give a higher number of reported adverse events than in studies using retrospective recordings. The most frequently reported side effect was dizziness or lightheadedness, a well known side effect of $\delta$-9-tetrahydrocannabinol, which has also been found to be more frequent during active treatment than during placebo treatment in other studies. ${ }^{29}$ In a previous study including multiple sclerosis patients the drug was reported to be well tolerated, with no difference in the number of side effects between dronabinol and placebo. ${ }^{46}$ Other studies, however, indicate that the clinical relevance of $\delta$-9-tetrahydrocannabinol as pain management may be limited by unfavourable adverse events. $^{47-49}$ 


\section{What is already known on this topic}

Cannabinoids reduce hyperalgesia in animal models of neuropathic, inflammatory, and cancer pain

Evidence from randomised controlled trials of the analgesic effect of cannabinoids in humans is sparse

A recent large study with pain as a secondary outcome measure indicated that cannabinoids may alleviate unspecified pain in multiple sclerosis

\section{What this study adds}

Dronabinol has a modest but clear and clinically relevant analgesic effect in multiple sclerosis patients with central pain

The effect size is comparable to that of other treatment options available

Dronabinol should be available for patients whose central pain is not sufficiently treated with alternative drugs such as anticonvulsants, antidepressants, or opioids

\section{Conclusion}

Oral dronabinol reduced central pain in patients with multiple sclerosis. Spontaneous pain intensity was reduced and pain relief was higher during dronabinol treatment than during placebo treatment, pressure evoked pain tended to decrease, and the patients tended to score better in the bodily pain domain of the health related quality of life questionnaire.

We thank chief consultants Hans Jacob Hansen and Thor Petersen at the multiple sclerosis clinic, Aarhus University Hospital, Denmark, for informing patients about the study and senior statistician Arne Andreasen for statistical support.

Contributors: KBS designed the study, collected data, participated in data analyses, and wrote most of the paper. TSJ initiated the study, participated in the design, and contributed to the writing of the paper. FWB initiated the study, participated in the design, advised on data collection, participated in data analyses, and contributed to the writing of the paper. FWB will act as guarantor for the paper. The guarantor accepts full responsibility for the conduct of the study, had access to the data, and controlled the decision to publish.

Funding: The study was supported by grants from the Danish Multiple Sclerosis Society (grant no 2002/71045), grant 900035 from manager Ejnar Jonasseon and his wife's memorial grant, and the Warwara Larsen Foundation (grant no 664.28), Denmark. Solvay Pharmaceuticals provided study medication (dronabinol (Marinol) and placebo capsules), labelling, and packaging. In addition, the company provided financial support for study monitoring and data analysis. IPC-Nordic, Denmark, packaged and labelled the study medication and monitored the study. These companies were not involved in the design or execution of the study or writing the manuscript.

Competing interests: None declared.

Ethical approval: The study was approved by the regional ethics committee (Aarhus, j.no.20010143), the Danish Medicines Agency (J.no.2612-170), and the Danish Data Protection Agency.

1 Archibald CJ, McGrath PJ, Ritvo PG, Fisk JD, Bhan V, Maxner CE, et al. Pain prevalence, severity and impact in a clinic sample of multiple sclerosis patients. Pain 1994;58:89-93. Clifford DB, Trotter JL. Pain in multiple sclerosis. Arch Neurol 1984;41:1270-2.

3 Moulin DE, Foley KM, Ebers GC. Pain syndromes in multiple sclerosis. Neurology $1988 ; 38: 1830-4$

4 Rae-Grant AD, Eckert NJ, Bartz S, Reed JF. Sensory symptoms of multiple sclerosis: a hidden reservoir of morbidity. Mult Scler 1999:5:179-83.

5 Stenager E, Knudsen L, Jensen K. Acute and chronic pain syndromes in multiple sclerosis. Acta Neurol Scand 1991;84:197-200.

6 Svendsen KB, Jensen TS, Overvad K, Hansen HJ, Koch-Henriksen N, Bach FW. Pain in patients with multiple sclerosis: a population-based study. Arch Neurol 2003;60:108994.
7 Boivie J. Central pain. In: Wall PD, Melzack R, eds. Textbook of pain. New York: Churchill Livingstone, 1999:879-914.

8 Jaggar SI, Hasnie FS, Sellaturay S, Rice AS. The anti-hyperalgesic actions of the cannabinoid anandamide and the putative CB2 receptor agonist palmitoylethanolamide in visceral and somatic inflammatory pain. Pain 1998;76:189-99.

9 Martin WJ, Loo CM, Basbaum AI. Spinal cannabinoids are anti-allodynic in rats with persistent inflammation. Pain 1999;82:199-205.

10 Bridges D, Ahmad K, Rice AS. The synthetic cannabinoid WIN55,212-2 attenuates hyperalgesia and allodynia in a rat model of neuropathic pain. $\mathrm{Br} J$ Pharmacol 2001:133:586-94.

11 Fox A, Kesingland A, Gentry C, McNair K, Patel S, Urban L, et al. The role of central and peripheral cannabinoid 1 receptors in the antihyperalgesic activity of cannabinoids in a model of neuropathic pain. Pain 2001;92:91-100.

12 Johanek LM, Heitmiller DR, Turner M, Nader N, Hodges J, Simone DA. Cannabinoids attenuate capsaicin-evoked hyperalgesia through spinal and peripheral mechanisms. Pain 2001;93:303-15.

13 Rukwied R, Watkinson A, McGlone F, Dvorak M. Cannabinoid agonists attenuate capsaicin-induced responses in human skin. Pain 2003;102:283-8.

14 Richardson JD, Kilo S, Hargreaves KM. Cannabinoids reduce hyperalgesia and inflammation via interaction with peripheral CB1 receptors. Pain 1998;75:111-9.

15 Kehl LJ, Hamamoto DT, Wacnik PW, Croft DL, Norsted BD, Wilcox GL, et al. A cannabinoid agonist differentially attenuates deep tissue hyperalgesia in animal models of cancer and inflammatory muscle pain. Pain 2003;103:175-86

16 Martin WJ, Coffin PO, Attias E, Balinsky M, Tsou K, Walker JM. Anatomical basis for cannabinoid-induced antinociception as revealed by intracerebral microinjections. Brain Res 1999;822:237-42.

17 Richardson JD, Aanonsen L, Hargreaves KM. Antihyperalgesic effects of spinal cannabinoids. Eur J Pharmacol 1998;345:145-53.

18 Nackley AG, Suplita RL, Hohmann AG. A peripheral cannabinoid mechanism suppresses spinal fos protein expression and pain behavior in a rat model of inflammation. Neuroscience 2003;117:659-70

19 Ross RA, Coutts AA, McFarlane SM, Anavi-Goffer S, Irving AJ, Pertwee RG, et al. Actions of cannabinoid receptor ligands on rat cultured sensory neurones: Actions of cannabinoid receptor ligands on rat cultured sen
implications for antinociception. Neuropharmacology 2001:40:221-32.

20 Walker JM, Hohmann AG, Martin WJ, Strangman NM, Huang SM, Tsou K. The neurobiology of cannabinoid analgesia. Life Sci 1999;65:665-73.

21 Holdcroft A, Smith M, Jacklin A, Hodgson H, Smith B, Newton M, et al. Pain relief with oral cannabinoids in familial Mediterranean fever. Anaesthesia 1997;52:483-6.

22 Notcutt W, Price M, Chapman G. Clinical experience with nabilone for chronic pain Pharm Sci 1997;3:551-5.

23 Hamann W, di Vadi PP. Analgesic effect of the cannabinoid analogue nabilone is not mediated by opioid receptors. Lancet 1999;353:560.

24 Noyes RJ, Brunk SF, Baram DA, Canter A. Analgesic effect of delta-9tetrahydrocannabinol. J Clin Pharmacol 1975;15:139-43.

25 Jain AK, Ryan JR, McMahon FG, Smith G. Evaluation of intramuscular levonantradol and placebo in acute postoperative pain. J Clin Pharmacol 1981;21:320-6S.

26 Buggy DJ, Toogood L, Maric S, Sharpe P, Lambert DG, Rowbotham DJ. Lack of analgesic efficacy of oral delta-9-tetrahydrocannabinol in postoperative pain. Pain 2003;106:169-72.

27 Karst M, Salim K, Burstein S, Conrad I, Hoy L, Schneider U. Analgesic effect of the synthetic cannabinoid CT-3 on chronic neuropathic pain: a randomized controlled trial. JAMA 2003;290:1757-62.

28 Wade DT, Robson P, House H, Makela P, Aram J. A preliminary controlled study to determine whether whole-plant cannabis extracts can improve intractable neurogenic symptoms. Clin Rehabil 2003;17:21-9.

29 Zajicek J, Fox P, Sanders H, Wright D, Vickery J, Nunn A, et al. Cannabinoids for treatment of spasticity and other symptoms related to multiple sclerosis (CAMS study): multicentre randomised placebo-controlled trial. Lancet 2003;362:1517-26.

30 Poser CM, Paty DW, Scheinberg L, McDonald WI, Davis FA, Ebers GC, et al. New diagnostic criteria for multiple sclerosis: guidelines for research protocols. Ann Neurol 1983;13:227-31.

31 Merskey H, Bogduk N, eds. Classification of chronic pain: descriptions of chromic pain syndromes and definitions of pain terms prepared by the International Association for the Stud of Pain, Task Force of Taxomomy. Seattle: IASP Press, 1994.

32 Kurtzke JF. Rating neurologic impairment in multiple sclerosis: an expanded disability status scale (EDSS). Neurology 1983;33:1444-52.

33 Goldberg JM, Lindblom U. Standardised method of determining vibratory perception thresholds for diagnosis and screening in neurological investigation.J J Neurol Neurosurg Psychiatry 1979;42:793-803.

34 Jensen TS, Bach FW, Kastrup J, Dejgaard A, Brennum J. Vibratory and thermal thresholds in diabetics with and without clinical neuropathy. Acta Neurol Scand 1991;84:32633.

35 Brennum J, Kjeldsen M, Jensen K, Jensen TS. Measurements of human pressure-pain thresholds on fingers and toes. Pain 1989;38:211-7.

36 Gottrup H, Kristensen AD, Bach FW, Jensen TS. Aftersensations in experimental and clinical hypersensitivity. Pain 2003;103:57-64.

37 Bjorner JB, Damsgaard MT, Watt T, Bech P, Rasmussen NK, Kristensen TS, et al. [Dan ish manual to SF-36] Copenhagen: Lif, 1997. (In Danish.)

38 Cook RJ, Sackett DL. The number needed to treat: a clinically useful measure of treatment effect. BMJ 1995;310:452-4

39 Senn S. Cross-over trials in clinical research. Chichester: John Wiley, 2002

40 Vestergaard K, Andersen G, Gottrup H, Kristensen BT, Jensen TS. Lamotrigine for central poststroke pain: a randomized controlled trial. Neurology 2001;56:184-90.

41 Lachin JM. Introduction to sample size determination and power analysis for clinical trials. Control Clin Trials 1981;2:93-113.

42 Finnerup NB, Gottrup H,Jensen TS. Anticonvulsants in central pain. Expert Opin Phar macother 2002:3:1411-20.

43 Sindrup SH, Jensen TS. Efficacy of pharmacological treatments of neuropathic pain: an update and effect related to mechanism of drug action. Pain 1999;83:389-400.

44 Gimbel JS, Richards P, Portenoy RK. Controlled-release oxycodone for pain in diabetic neuropathy: a randomized controlled trial. Neurology 2003;60:927-34.

45 Farrar JT, Portenoy RK, Berlin JA, Kinman JL, Strom BL. Defining the clinically important difference in pain outcome measures. Pain 2000;88:287-94. 
46 Killestein J, Hoogervorst EL, Reif M, Kalkers NF, Van Loenen AC, Staats PG, et al. Safety, tolerability, and efficacy of orally administered cannabinoids in MS. Neurology 2002;58:1404-7

47 Clermont-Gnamien S, Atlani S, Attal N, Le MF, Guirimand F, Brasseur L. [The therapeutic use of D9-tetrahydrocannabinol (dronabinol) in refractory neuropathic pain.] Presse Med 2002;31:1840-5. (In French.)

48 Noyes RJ, Brunk SF, Avery DA Canter AC The analgesic properties of delta-9-tetrahydrocannabinol and codeine. Clin Pharmacol Ther 1975;18:84-9.

49 Campbell FA, Tramer MR, Carroll D, Reynolds DJ, Moore RA, McQuay HJ. Are cannabinoids an effective and safe treatment option in the management of pain? A qualitative systematic review. BMJ 2001;323:13-6.
(Accepted 12 May 2004)

doi 10.1136/bmj.38149.566979.AE

Danish Pain Research Center and Department of Neurology, Aarhus University Hospital, Noerrebrogade 44, DK-8000 Aarhus C, Denmark

Kristina B Svendsen research fellow

Troels S Jensen professor

Flemming W Bach associate clinical professor

Correspondence to: F W Bach fbach@akh.aaa.dk 